\title{
Experimental investigation of Surface roughness of cylinder liner for HT 100 material using RSM Technique
}

\author{
Mr. B.N.Tripathi \\ Research Scholar Deptt. of Mech. Engg. ISM Dhanbad India \\ Dr. N.K. Singh \\ Associate Professor (Workshop) Deptt. of Mech. Engg ISM Dhanbad India
}

\begin{abstract}
Surface roughness of any manufactured components is an important and valuable performance measured, as for as theoretical and practical applications are concern. It is widely used as an index of product quality and is in most cases a technical requirement for mechanical products. Surface roughness is an important design consideration as it impacts many part characteristics such as fatigue strength, assembly tolerances, coefficient of friction, wear rate, corrosion resistance and aesthetics. In the present study honing process is done on the HT 100 and the response surface methodology is used to validate the results.
\end{abstract}

Keywords: Honing Process, Surface roughness, RSM technique.

\section{Introduction \\ Surface Roughness}

The concept of surface texture has previously varied according to whether a scientist, technologist, or engineer has inspected a surface. Surface technology encompasses a wide range of disciplines that include: metrology, metallurgy, material science, physics, chemistry and mechanical design (Staut, 1984). Surface roughness affects mechanical and even electrical properties of a given component such as electrical capacity, electronic conductivity, surface energy, critical areas, peak electrical field, surface tension, and sheet resistance. Surface finish in fact determines the performance and reliability of many products (Kardar, 2000). The surface is the final link from the original design concept through its manufacture, with the industrial engineer being the last person to add value to the product prior to shipment (PDI Webmaster, 2004). Surface roughness is a quantitative measure of the marks produced by the process of creation of the surface. Other factors such as the structure of the material also influence roughness of the surface. Waviness or lay has longer wavelength and is related to the vibration of the finishing machine. Industry is continually trying to improve component power-to-weight ratios, drive down manufacturing costs and find efficient ways of either producing or improving surfaces. This has become an established goal of world-class competing companies. Regardless of the method of manufacture, an engineering surface must have some form of texture associated with it, this being a combination of several interrelated factors, such as microstructure of the material of component, the surface generation method, cutting action of the tool, tool geometry, cutting speed, feed rate, and application of cutting fluid, instability during the manufacturing process, and residual stress produced by stress patterns often causing deformations in the component (Mantle and Aspinwall, 2001).

\section{Honing Process}

Honing is a fine finishing abrasive machining process with a multi-edge cutting tool of bonded grains under constant surface contact between tool and pre-machined components, which offers good geometrical tolerances (Kalpakjian and Schmid, 2003). It is a controlled, low speed sizing and surface finishing process in which stock is removed by the shearing and plugging action. Selection of honing stone and grit size depends mainly on the desired rate of metal removal and the required finish. Abrasive material of the hone is chosen on the basis of the composition and hardness of the metal being honed and the finish required. The selection of a particular honing machine depends on the size and shape of the work piece, number of pieces to be honed, tolerance requirement, availability of equipment, and availability of skilled workers. Honing provides a cost effective alternative to other finishing processes like grinding, lapping and super finishing (Leon, 2002).

\section{Response Surface Methodology}

Response Surface Methodology (RSM) is a collection of statistical and mathematical techniques useful for developing, improving, and optimizing processes.

The most extensive applications of RSM are in the particular situations where several input variables potentially influence some performance measure or quality characteristic of the process. Thus performance measure or quality characteristic is called the response. The input variables are sometimes called independent variables, and they are subject to the control of the scientist or engineer. The field of response surface methodology consists of the experimental strategy for exploring the space of the process or independent variables, empirical statistical modelling to develop an appropriate approximating relationship between the yield and the process variables, and optimization methods for finding the values of the process variables that produce desirable values of the response. In this report we will concentrate on the second strategy: statistical modelling to develop an appropriate approximating model between the response $y$ and independent variables $\xi_{1}, \xi_{2}, \ldots, \xi_{\mathrm{K}}$.

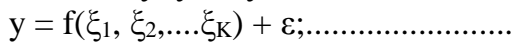


where the form of the true response function $f$ is unknown and perhaps very complicated, and $\varepsilon$ is a term that represents other sources of variability not accounted for in $f$. Usually $\varepsilon$ includes effects such as measurement error on the response, background noise, the effect of other variables, and so on. Usually $\varepsilon$ is treated as a statistical error, often assuming it to have a normal distribution with mean zero and variance $\left(\sigma^{2}\right)$. The true response function $f$ is unknown, we must approximate it. In fact, successful use of RSM is critically dependent upon the experimenter's ability to develop a suitable approximation forf. usually, a low-order polynomial in some relatively small region of the independent variable space is appropriate. In many cases, either a first-order or a second order model is used. The first-order model is likely to be appropriate when the experimenter is interested in approximating the true response surface over a relatively small region of the independent variable space in a location where there is little curvature in $f$. This is the first-order model with interaction. Adding the interaction term introduces curvature into the response function.

Often the curvature in the true response surface is strong enough that the first-order model (even with the interaction term included) is inadequate. A second-order model will likely be required in these situations. For the case of two variables, the second-order model is give as-

$\eta=\beta o+\beta_{1} x_{1}+\beta 2 x_{2}+\beta 11 x_{1}^{2}+\beta 22 x^{2}+\beta 12 x_{1} x_{2} ;$

This model would likely be useful as an approximation to the true response surface in a relatively small region. The secondorder model is widely used in response surface methodology for several reasons:

1. The second-order model is very flexible. It can take on a wide variety of functional forms, so it will often work well as an approximation to the true response surface.

2. It is easy to estimate the parameters (the $\beta$ 's) in the second-order model. The method of least squares can be used for this purpose.

3. There is considerable practical experience indicating that second-order models work well in solving real response surface problems.

\section{Sequential Nature of Response Surface Methodology}

Most applications of RSM are sequential in nature.

Phase 0: At first some ideas are generated concerning which factors or variables are likely to be important in response surface study. It is usually called a screening experiment. The objective of factor screening is to reduce the list of candidate variables to a relatively few so that subsequent experiments will be more efficient and require fewer runs or tests. The purpose of this phase is the identification of the important independent variables.

Phase 1: The experimenter's objective is to determine if the current settings of the independent variables result in a value of the response that is near the optimum. If the current settings or levels of the independent variables are not consistent with optimum performance, then the experimenter must determine a set of adjustments to the process variables that will move the process toward the optimum. This phase of RSM makes considerable use of the first-order model and an optimization technique called the method of steepest ascent (descent).

Phase 2: Phase 2 begins when the process is near the optimum. At this point the experimenter usually wants a model that will accurately approximate the true response function within a relatively small region around the optimum. Because the true response surface usually exhibits curvature near the optimum, a second-order model (or perhaps some higher-order polynomial) should be used. Once an appropriate approximating model has been obtained, this model may be analyzed to determine the optimum conditions for the process. This sequential experimental process is usually performed within some region of the independent variable space called the operability region or experimentation region or region of interest.

\section{RSM as an Automated Tool for Modelling \& Validation}

Modern computational large scale social networks simulation systems are becoming heavily used due to their efficiency and flexibility in modelling and simulation of complex social networks. Since these models are increasing in complexity and size they require more significant time and efforts for their validation, optimization, improvement and understanding of their behaviour. One example of such multi-agent socialnetwork model named Bio War is presented spatial city-scale multi-agent social-network model capable of simulating the effects of biological weapon attacks against the background of naturally-occurring diseases on demographically realistic population. Response Surface Methodology (RSM) might be extremely useful as an automated tool that can be used to calibrate such multi-agent models as Bio War, and facilitate validation and understanding, thereby increasing model fidelity and reliability and giving the user some feedback for analysis and insight.

Every simulation model has its own specific that should be taken into consideration when we try to specify independent and dependent variables. For example, within ORA the RSM tool can use one group of measures like a person's height, age, weight as independent variables and another like the amount of money earned as the dependent variable. We can also consider some of DNA measures like Resource Congruence or Task Exclusivity as independent variables while some other DNA measure like Network Closeness Centralization can serve as dependent variable. If the RSM is operating on the node level measures then independent variables can be any node level measure. There is a particular interest also in consideration of some means or standard deviations of the graph level measures as dependent or independent variables.

The RSM is also useful for searching the input combination that maximizes the output of areal system or its simulation such as Bio War or ORA. When validating or optimizing a stochastic simulation model, one tries to estimate the model parameters that optimize specific stochastic output of the simulation model. A simulation framework is especially intended for simulation models where the calculation of the corresponding stochastic objective function is very expensive or time-consuming. RSM is frequently used for the optimization of stochastic simulation models. This methodology is based on approximation of the stochastic 
objective function by a low order polynomial on a small sub region of the domain. The coefficients of the polynomial are estimated by ordinary least squares method applied to a number of observations of the stochastic objective function. To this end, the objective function is evaluated in an arrangement of points referred to as an experimental design. Based on the fitted polynomial, the local best point is derived, which is used as a current estimator of the optimum and as a centre point of a new region of experimentation, where again the stochastic objective function is approximated by a low order polynomial. In non-automated optimization, RSM is an interactive process in which the user gradually gains understanding of the nature of the stochastic objective function. In an automated RSM algorithm, however, human intervention during the optimization process is excluded. A good automated RSM algorithm should therefore include some degree of self-correction mechanisms factors as noise factors. RSM assumes that these noise factors are uncontrollable in the field, but can be controlled during process development for purposes of a designed experiment Considerable attention has been focused on the methodology advocated by Taguchi, and a number of flaws in his approach have been discovered.

\section{Experimental setup:}

Honing is an abrasive machining process that produces a precision surface on a metal work piece by scrubbing an abrasive stone against it along a controlled path. Honing is primarily used to improve the geometric form of a surface, but may also improve the surface texture. The honing process is used to obtain precise dimensions and surfaces in cylindrical shapes with a wide range of diameters. This applies to parts such as Hydraulic Cylinders, Pistons, Bearing Bores, Pin Holes and to some external cylindrical surfaces. The honing process offers advantages of low capital equipment cost, high metal removal rates, and extreme accuracy of $0.001 \mathrm{~mm}$ $\left(0.00004^{\prime \prime}\right)$ in a wide variety of materials. Honing machines are available in a wide range of sizes and designs, in both horizontal and vertical types. They may be equipped with either manual stroking or power stroking mechanisms. Size and shape of the work piece are usually the major factors that determine whether manual or power stroking is more appropriate. Other relevant factors are the quantity of similar pieces to be honed, tolerance requirements, availability of skilled operators, and specific plant policies. Most bores honed by manual stroking are $25 \mathrm{~mm}$ in diameter or less, although bores up to about $127 \mathrm{~mm}$ in diameter have been successfully finished. The bore diameter of the cylinder liner chosen for the present study $47 \mathrm{~mm}$. Power stroking with automatic control is used in preference for large quantities when tolerances are extremely close and size and shape of the work piece permit it. One advantage of manual stroking is that work pieces need not be held in a fixture, which reduces tooling investment and permits immediate changeover from one job to another. Automatic honing operation is the best technique than manual, who can instantly gage the part, close tolerances can be obtained. Techniques used to obtain the required accuracy required include end for end reversal of the work piece and change of stroke length.
In automatic power stroking, the machine rotates the tool at a preset speed as control parameters feed in to the control units. Because the axis of the honing tool is horizontal, stroking is also horizontal. These machines may be equipped with devices for controlled feed out of the honing stones. The manufacturing plant, where experiments for the present study were conducted, utilized a vertical type power stroking honing machine for finishing the liner bore. The experiments were run on a CNC operated honing machine, model HONSD,SL NO-210, (F:08:0023:02) having the facilities to hold the work piece within the place provided by the help of fixture, sketched shown in Fig. 1. Technical specifications of the above honing machine are given in the Table 1 . The above machine rotated the honing tool at a pre-established speed while the work piece had lateral movement. It was stroked back and forth over the tool. The machine was equipped with devices for controlled feed out of the honing stones.

The operator loads the job on the hone tool and presses the pedal. The honing tool starts rotating and operator reciprocates the job manually. This manual cycle is continued till the time set for honing is over. Different types and grits of stones are used depending upon the material removal and surface finish requirement.

\section{TABLE 1: Technical specifications of HONS 210}

\begin{tabular}{|l|l|}
\hline MODEL & HONSD,SL NO-210, (F:08:0023:02) \\
\hline Honing Operation & Power Stroking \\
\hline Capacity: Diameter & $13-85 \mathrm{~mm}$ \\
\hline Capacity: Length & $250 \mathrm{~mm}$ \\
\hline Spindle speed & $250-1660 \mathrm{rpm}$ \\
\hline Reciprocation speed & Automatic, CNC controlled \\
\hline Spindle drive motor & $1.5 \mathrm{HP} .1660 \mathrm{rpm}$ \\
\hline
\end{tabular}
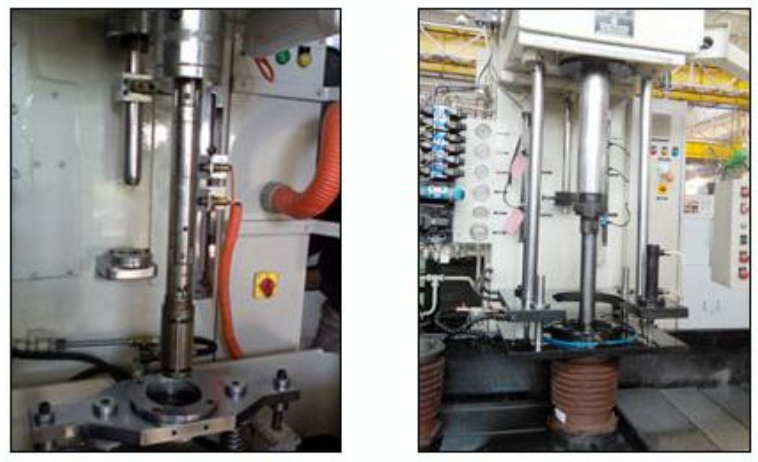

Fig. 1: Honing Head with Tooling (Honda Ltd. Gurgaon)

The operating cycle is repeated from part to part. The expanding mechanism of the honing tool is set for size on the first part and, except for a slight advance of the stone to compensate for wear; additional parts require no resetting of controls. Honing stones are also known as honing sticks. Honing stones used in the present study had grits of aluminums oxide bonded together with vitrified clay, 
resinous, cork, carbon, or metal. The abrasive particles, or grits, which provide the cutting action, are able to withstand the pressure required for removing the excess metal from the bore. The bond is strong enough to hold the grit, but not too hard to excessively retard cutting action. The hardness and type of bond are indicated by code letters in the identification of the stone. The porosity of the honing stone, which facilitates chip clearance and minimizes heat generation, is controlled during molding.

Selection of abrasive for the stones depends mainly on the composition and hardness of the metal being honed, the finish required and the cost. Aluminum oxide and silicon carbide stones are comparable in initial cost. However, one may be more economical than the other because of increased service life. Aluminum oxide abrasive has been selected for honing the work piece materials HT 100 used for the chosen part. The range of the grits used for the experiments lies between 4001000 .

\section{Experimental Procedure:}

1. Mandrel, adaptor and stone are assembled and mounted in the chuck of the machine.

2. Machine is switched on and speed control is set to the required value.

3. Stone feed is set at the chosen value.

4. Honing stone is fully retracted by rotating feed wheel anti-clockwise.

5. Honing fluid flow is adjusted and environmental temperature maintained as per requirement using Air-conditioning plant.

6. Cylinder liner is placed on the mandrel. Feed is adjusted until the clock shows a reading as per the desired value.

7. Stone feed is wound by the amount needed to produce size, i.e. equal to the honing allowance.

8. Start the spindle rotating and power stroking up to the time set for honing.

9. Remove the work piece after honing for the given time, at rated speed.

10. Repeat the process for another set for readings by changing the parameters as per the design of experiments.

\section{Experimental Observations \\ Factors and levels of experiment for modeling}

Five levels of each parameter (including positive and negative value of alpha) were taken for the model construction. Three (03) different set of experiments (readings) were conducted on the same level. Three different set of experiments were conducted on each material cylinder liner as per the DOE, which able to capture non-linear effects using Design Expert 8.The values of factor levels in different sets of experiments are listed in Table 2 through 4
TABLE 2: HT 100-Factors and levels for $1^{\text {st }}$ set of readings

\begin{tabular}{|c|c|c|c|c|c|c|c|c|}
\hline SL & $\begin{array}{l}\text { Grit } \\
\text { Size } \\
(\mu \mathrm{m}) \\
\end{array}$ & \begin{tabular}{|c|} 
Environ \\
mental \\
Temp. $\left({ }^{\circ} \mathrm{C}\right)$
\end{tabular} & $\begin{array}{c}\text { Rotational } \\
\text { Speed } \\
\text { (RPM) }\end{array}$ & $\begin{array}{l}\text { Hone } \\
\text { Angle } \\
\text { (Deg.) }\end{array}$ & \begin{tabular}{|c|}
$\begin{array}{c}\text { Fluid } \\
\text { Pressure } \\
\text { (Bar) }\end{array}$ \\
\end{tabular} & \begin{tabular}{|l|} 
Honing \\
Time \\
(Sec.) \\
\end{tabular} & $\begin{array}{c}R_{a} \\
(n m)\end{array} \mid$ & $\begin{array}{l}\text { Power } \\
(\text { Kw })\end{array}$ \\
\hline \begin{tabular}{|l|}
1 \\
\end{tabular} & 43 & 40 & 600 & 60 & 9 & 60 & 325 & 1.8 \\
\hline 2 & 68 & 10 & 600 & 20 & 4 & 60 & 456 & 3.6 \\
\hline 3 & 68 & 10 & 600 & 20 & 9 & 30 & 529 & 3.7 \\
\hline 4 & 43 & 10 & 1200 & 60 & 4 & 30 & 276 & 1.5 \\
\hline \begin{tabular}{|l|}
5 \\
\end{tabular} & 68 & 10 & 600 & 60 & 4 & 30 & 433 & 2.9 \\
\hline \begin{tabular}{|l|}
6 \\
\end{tabular} & 43 & 10 & 600 & 20 & 4 & 30 & 446 & 1.7 \\
\hline \begin{tabular}{|l|}
7 \\
\end{tabular} & 43 & 40 & 1200 & 20 & 4 & 30 & 303 & 2.2 \\
\hline \begin{tabular}{|l|}
8 \\
\end{tabular} & 56 & 25 & 900 & 40 & 6.5 & 45 & 388 & 3.1 \\
\hline \begin{tabular}{|l|}
9 \\
\end{tabular} & 56 & 25 & 900 & 40 & 6.5 & 45 & 370 & 3.1 \\
\hline 10 & 56 & 25 & 900 & 40 & 6.5 & 45 & 381 & 3 \\
\hline 11 & 68 & 40 & 600 & 60 & 4 & 60 & 519 & 3.9 \\
\hline 12 & 68 & 10 & 1200 & 20 & 4 & 30 & 452 & 3 \\
\hline 13 & 68 & 10 & 1200 & 60 & 9 & 30 & 422 & 3.3 \\
\hline 14 & 68 & 10 & 1200 & 20 & 9 & 60 & 502 & 3.8 \\
\hline 15 & 43 & 40 & 1200 & 20 & 9 & 60 & 296 & 2.2 \\
\hline 16 & 68 & 40 & 600 & 20 & 4 & 30 & 363 & 3.3 \\
\hline \begin{tabular}{|l|}
17 \\
\end{tabular} & 68 & 40 & 1200 & 60 & 9 & 60 & 526 & 4.3 \\
\hline \begin{tabular}{|l|}
18 \\
\end{tabular} & 43 & 10 & 1200 & 60 & 9 & 60 & 310 & 2.6 \\
\hline 19 & 68 & 10 & 1200 & 60 & 4 & 60 & 395 & 2.8 \\
\hline 20 & 56 & 25 & 900 & 40 & 6.5 & 45 & 357 & 2.3 \\
\hline 21 & 68 & 40 & 600 & 60 & 9 & 30 & 534 & 4 \\
\hline 22 & 56 & 25 & 900 & 40 & 6.5 & 45 & 368 & 2.9 \\
\hline 23 & 68 & 40 & 1200 & 20 & 9 & 30 & 553 & 3.5 \\
\hline 24 & 56 & 25 & 900 & 40 & 6.5 & 45 & 377 & 2.9 \\
\hline \begin{tabular}{|l|}
25 \\
\end{tabular} & 56 & 25 & 900 & 40 & 6.5 & 45 & 395 & 2.9 \\
\hline 26 & 43 & 10 & 600 & 20 & 9 & 60 & 402 & 2 \\
\hline 27 & 43 & 10 & 1200 & 20 & 9 & 30 & 340 & 1.6 \\
\hline 28 & 68 & 40 & 600 & 20 & 4 & 60 & 335 & 3.4 \\
\hline 29 & 68 & 40 & 600 & 20 & 9 & 30 & 430 & 2.9 \\
\hline 30 & 43 & 10 & 600 & 60 & 9 & 30 & 449 & 1.8 \\
\hline 31 & 43 & 10 & 600 & 60 & 9 & 60 & 377 & 3.4 \\
\hline 32 & 43 & 10 & 600 & 60 & 4 & 60 & 328 & 2.2 \\
\hline \begin{tabular}{|l|}
33 \\
\end{tabular} & 68 & 40 & 1200 & 60 & 4 & 60 & 445 & 3.1 \\
\hline 34 & 43 & 10 & 1200 & 20 & 4 & 60 & 174 & 2.5 \\
\hline 35 & 56 & 25 & 900 & 40 & 6.5 & 45 & 356 & 2.9 \\
\hline 36 & 68 & 40 & 600 & 20 & 9 & 60 & 363 & 3.4 \\
\hline 37 & 68 & 40 & 1200 & 60 & 9 & 30 & 487 & 2.5 \\
\hline 38 & 68 & 40 & 600 & 60 & 4 & 30 & 344 & 2.5 \\
\hline 39 & 68 & 40 & 1200 & 20 & 4 & 60 & 466 & 2.7 \\
\hline 40 & 68 & 40 & 1200 & 60 & 4 & 30 & 444 & 2.4 \\
\hline 41 & 56 & 25 & 900 & 40 & 6.5 & 15 & 577 & 0.7 \\
\hline \begin{tabular}{|l|}
42 \\
\end{tabular} & \begin{tabular}{|l|}
56 \\
\end{tabular} & 25 & 900 & 0 & 6.5 & 45 & 659 & 2.1 \\
\hline \begin{tabular}{|l|}
43 \\
\end{tabular} & 56 & 25 & 1500 & 40 & 6.5 & 45 & 273 & 2.2 \\
\hline 44 & 56 & 55 & 900 & 40 & 6.5 & 45 & 355 & 2.2 \\
\hline 45 & 56 & 25 & 900 & 40 & 1.5 & 45 & 236 & 2.2 \\
\hline \begin{tabular}{|l|}
46 \\
\end{tabular} & 56 & 25 & 900 & 40 & 6.5 & 45 & 369 & 2.1 \\
\hline 47 & 31 & 25 & 900 & 40 & 6.5 & 45 & 140 & 1.7 \\
\hline 48 & 81 & 25 & 900 & 40 & 6.5 & 45 & 738 & 4.9 \\
\hline \begin{tabular}{|l|}
49 \\
\end{tabular} & 56 & 25 & 900 & 40 & 6.5 & 45 & 387 & 2.0 \\
\hline 50 & 56 & 25 & 900 & 80 & 6.5 & 45 & 343 & 2.1 \\
\hline \begin{tabular}{|l|}
51 \\
\end{tabular} & 56 & 25 & 900 & 40 & 6.5 & 75 & 302 & 3.2 \\
\hline \begin{tabular}{|l|}
52 \\
\end{tabular} & 56 & 25 & 300 & 40 & 6.5 & 45 & 561 & 1.9 \\
\hline 53 & 56 & 25 & 900 & 40 & 11.5 & 45 & 498 & 1.8 \\
\hline \begin{tabular}{|l|}
54 \\
\end{tabular} & 56 & -5 & 900 & 40 & 6.5 & 45 & 286 & 1.6 \\
\hline
\end{tabular}


International Journal of Applied Engineering Research ISSN 0973-4562 Volume 10, Number 18 (2015) pp 39239-39246

(C) Research India Publications. https://dx.doi.org/10.37622/IJAER/10.18.2015.39239-39246

TABLE 3: HT 100-Factors and levels for $2^{\text {nd }}$ set of readings

\begin{tabular}{|c|c|c|c|c|c|c|c|c|}
\hline SL & Grit & \begin{tabular}{|c|} 
Environ \\
mental \\
Temp. \\
$\left({ }^{\circ} \mathrm{C}\right)$ \\
\end{tabular} & $\begin{array}{c}\text { Rotational } \\
\text { Speed } \\
\text { (RPM) }\end{array}$ & $\begin{array}{l}\text { Hone } \\
\text { Angle } \\
\text { (Deg.) }\end{array}$ & $\begin{array}{c}\text { Fluid } \\
\text { Pressure } \\
\text { (Bar) }\end{array}$ & $\left|\begin{array}{c}\text { Honing } \\
\text { Time } \\
\text { (Sec.) }\end{array}\right|$ & $\left(\begin{array}{c}R_{a} \\
(n m)\end{array}\right)$ & $\begin{array}{l}\text { Power } \\
(\text { Kw })\end{array}$ \\
\hline \begin{tabular}{|l|} 
\\
\end{tabular} & 43 & 40 & 600 & 60 & 9 & 60 & 340 & 1.8 \\
\hline 2 & 68 & 10 & 600 & 20 & 4 & 60 & 465 & 3.6 \\
\hline \begin{tabular}{|l|}
3 \\
\end{tabular} & 68 & 10 & 600 & 20 & 9 & 30 & 524 & 3.7 \\
\hline \begin{tabular}{|l|}
4 \\
\end{tabular} & 43 & 10 & 1200 & 60 & 4 & 30 & 290 & 1.5 \\
\hline 5 & 68 & 10 & 600 & 60 & 4 & 30 & 421 & 2.9 \\
\hline \begin{tabular}{|l|l|}
6 \\
\end{tabular} & 43 & 10 & 600 & 20 & 4 & 30 & 458 & 1.7 \\
\hline 7 & 43 & 40 & 1200 & 20 & 4 & 30 & 308 & 2.2 \\
\hline \begin{tabular}{|l|}
8 \\
\end{tabular} & 56 & 25 & 900 & 40 & 6.5 & 45 & 383 & 3.1 \\
\hline \begin{tabular}{|l|}
9 \\
\end{tabular} & 56 & 25 & 900 & 40 & 6.5 & 45 & 373 & 3.1 \\
\hline 10 & 56 & 25 & 900 & 40 & 6.5 & 45 & 385 & 3 \\
\hline 11 & 68 & 40 & 600 & 60 & 4 & 60 & 517 & 3.9 \\
\hline 12 & 68 & 10 & 1200 & 20 & 4 & 30 & 458 & 3.2 \\
\hline 13 & 68 & 10 & 1200 & 60 & 9 & 30 & 420 & 3.3 \\
\hline 14 & 68 & 10 & 1200 & 20 & 9 & 60 & 507 & 3.5 \\
\hline 15 & 43 & 40 & 1200 & 20 & 9 & 60 & 294 & 2.2 \\
\hline 16 & 68 & 40 & 600 & 20 & 4 & 30 & 370 & 3.3 \\
\hline 17 & 68 & 40 & 1200 & 60 & 9 & 60 & 535 & 4.3 \\
\hline 18 & 343 & 10 & 1200 & 60 & 9 & 60 & 313 & 2.6 \\
\hline 19 & 68 & 10 & 1200 & 60 & 4 & 60 & 398 & 2.8 \\
\hline 20 & 56 & 25 & 900 & 40 & 6.5 & 45 & 358 & 2.3 \\
\hline 21 & 68 & 40 & 600 & 60 & 9 & 30 & 539 & 4.1 \\
\hline 22 & 56 & 25 & 900 & 40 & 6.5 & 45 & 367 & 2.9 \\
\hline 23 & 68 & 40 & 1200 & 20 & 9 & 30 & 555 & 3.5 \\
\hline 24 & 56 & 25 & 900 & 40 & 6.5 & 45 & 378 & 2.9 \\
\hline 25 & 56 & 25 & 900 & 40 & 6.5 & 45 & 390 & 2.9 \\
\hline 26 & 43 & 10 & 600 & 20 & 9 & 60 & 405 & 2.2 \\
\hline 27 & 43 & 10 & 1200 & 20 & 9 & 30 & 342 & 1.6 \\
\hline 28 & 68 & 40 & 600 & 20 & 4 & 60 & 337 & 3.4 \\
\hline 29 & 68 & 40 & 600 & 20 & 9 & 30 & 434 & 2.9 \\
\hline 30 & 43 & 10 & 600 & 60 & 9 & 30 & 443 & 1.8 \\
\hline 31 & 43 & 10 & 600 & 60 & 9 & 60 & 370 & 3.4 \\
\hline 32 & 43 & 10 & 600 & 60 & 4 & 60 & 327 & 2.2 \\
\hline 33 & 68 & 40 & 1200 & 60 & 4 & 60 & 448 & 3.1 \\
\hline 34 & 43 & 10 & 1200 & 20 & 4 & 60 & \begin{tabular}{|l|}
171 \\
\end{tabular} & 2.5 \\
\hline 35 & 56 & 25 & 900 & 40 & 6.5 & 45 & 353 & 2.9 \\
\hline 36 & 68 & 40 & 600 & 20 & 9 & 60 & 365 & 3.4 \\
\hline 37 & 68 & 40 & 1200 & 60 & 9 & 30 & 482 & 2.5 \\
\hline 38 & 68 & 40 & 600 & 60 & 4 & 30 & 348 & 2.5 \\
\hline 39 & 68 & 40 & 1200 & 20 & 4 & 60 & 460 & 2.7 \\
\hline 40 & 68 & 40 & 1200 & 60 & 4 & 30 & 447 & 2.4 \\
\hline 41 & 56 & 25 & 900 & 40 & 6.5 & 15 & 580 & 0.7 \\
\hline 42 & 56 & 25 & 900 & 0 & 6.5 & 45 & 658 & 2 \\
\hline \begin{tabular}{|l|}
43 \\
\end{tabular} & 56 & 25 & 1500 & 40 & 6.5 & 45 & 279 & 2.2 \\
\hline 44 & 56 & 55 & 900 & 40 & 6.5 & 45 & 351 & 2.1 \\
\hline 45 & 56 & 25 & 900 & 40 & 1.5 & 45 & 237 & 2 \\
\hline \begin{tabular}{|l|}
46 \\
\end{tabular} & 56 & 25 & 900 & 40 & 6.5 & 45 & 363 & 2.1 \\
\hline 47 & 31 & 25 & 900 & 40 & 6.5 & 45 & 144 & 1.7 \\
\hline \begin{tabular}{|l|}
48 \\
\end{tabular} & 81 & 25 & 900 & 40 & 6.5 & 45 & 732 & 4.9 \\
\hline 49 & 56 & 25 & 900 & 40 & 6.5 & 45 & 381 & 2 \\
\hline 50 & 56 & 25 & 900 & 80 & 6.5 & 45 & 341 & 2.1 \\
\hline 51 & 56 & 25 & 900 & 40 & 6.5 & 75 & 306 & 3.2 \\
\hline 52 & 56 & 25 & 300 & 40 & 6.5 & 45 & 569 & 1.9 \\
\hline 53 & 56 & 25 & 900 & 40 & 11.5 & 45 & 492 & 1.8 \\
\hline 54 & 56 & -5 & 900 & 40 & 6.5 & 45 & 284 & 1.4 \\
\hline
\end{tabular}

TABLE 4: HT 100-Factors and levels for $3^{\text {rd }}$ set of readings

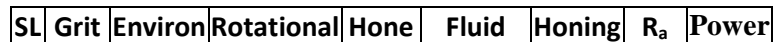
Size mental Speed Angle Pressure Time (nm) (Kw) $\begin{array}{lllll}(\mu \mathrm{m}) & \text { Temp } & \text { (RPM) } & \text { (Deg.) } & \text { (Bar) }\end{array}$

\begin{tabular}{|c|c|c|c|c|c|c|c|c|}
\hline & & $\left({ }^{\circ} \mathbf{C}\right)$ & & & & & & \\
\hline 1 & 43 & 40 & 600 & 60 & 9 & 60 & 334 & 1.7 \\
\hline
\end{tabular}

\begin{tabular}{|l|l|l|l|l|l|l|l|l|}
\hline 2 & 68 & 10 & 600 & 20 & 4 & 60 & 469 & 3.6 \\
\hline 3 & 68 & 10 & 600 & 20 & 9 & 30 & 522 & 3.7 \\
\hline
\end{tabular}

\begin{tabular}{|l|l|l|l|l|l|l|l|l|}
\hline 3 & 68 & 10 & 600 & 20 & 9 & 30 & 522 & 3.7 \\
\hline 4 & 43 & 10 & 1200 & 60 & 4 & 30 & 295 & 1.5 \\
\hline
\end{tabular}

\begin{tabular}{|l|l|l|l|l|l|l|l|l|}
\hline 4 & 43 & 10 & 1200 & 60 & 4 & 30 & 295 & 1.5 \\
\hline
\end{tabular}

\begin{tabular}{|l|l|l|l|l|l|l|l|l|}
\hline 5 & 68 & 10 & 600 & 60 & 4 & 30 & 422 & 2.7 \\
\hline & 43 & 10 & 600 & 20 & 4 & 30 & 458 & 1.7 \\
\hline
\end{tabular}

\begin{tabular}{|l|l|l|l|l|l|l|l|l|}
\hline 6 & 43 & 10 & 600 & 20 & 4 & 30 & 458 & 1.7 \\
\hline 7 & 43 & 40 & 1200 & 20 & 4 & 30 & 300 & 2.2 \\
\hline
\end{tabular}

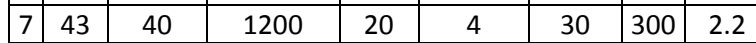

\begin{tabular}{|l|l|l|l|l|l|l|l|l|}
\hline 8 & 56 & 25 & 900 & 40 & 6.5 & 45 & 384 & 3.1 \\
\hline
\end{tabular}

\begin{tabular}{|l|l|l|l|l|l|l|l|l|}
\hline 9 & 56 & 25 & 900 & 40 & 6.5 & 45 & 382 & 3.1 \\
\hline
\end{tabular}

\begin{tabular}{|l|l|l|l|l|l|l|l|l|}
\hline 10 & 56 & 25 & 900 & 40 & 6.5 & 45 & 384 & 3.1 \\
\hline
\end{tabular}

\begin{tabular}{|l|l|l|l|l|l|l|l|l|}
\hline 11 & 68 & 40 & 600 & 60 & 4 & 60 & 519 & 3.9 \\
\hline 12 & 68 & 10 & 1200 & 20 & 4 & 30 & 454 & 3.0 \\
\hline
\end{tabular}

\begin{tabular}{|l|l|l|l|l|l|l|l|l|l|}
\hline 12 & 68 & 10 & 1200 & 20 & 4 & 30 & 454 & 3.0 \\
\hline 13 & 68 & 10 & 1200 & 60 & 9 & 30 & 429 & 3.3 \\
\hline
\end{tabular}

\begin{tabular}{|l|l|l|l|l|l|l|l|l|}
\hline 13 & 68 & 10 & 1200 & 60 & 9 & 30 & 429 & 3.3 \\
\hline 14 & 68 & 10 & 1200 & 20 & 9 & 60 & 503 & 3.8 \\
\hline
\end{tabular}

\begin{tabular}{|l|l|l|l|l|l|l|l|l|}
\hline 14 & 68 & 10 & 1200 & 20 & 9 & 60 & 503 & 3.8 \\
\hline
\end{tabular}

\begin{tabular}{|l|l|l|l|l|l|l|l|l|}
\hline 15 & 43 & 40 & 1200 & 20 & 9 & 60 & 285 & 2.2 \\
\hline 16 & 68 & 40 & 600 & 20 & 4 & 30 & 377 & 3.3 \\
\hline
\end{tabular}

\begin{tabular}{|l|l|l|l|l|l|l|l|l|}
\hline 16 & 68 & 40 & 600 & 20 & 4 & 30 & 377 & 3.3 \\
\hline
\end{tabular}

\begin{tabular}{|l|l|l|l|l|l|l|l|l|}
\hline 17 & 68 & 40 & 1200 & 60 & 9 & 60 & 534 & 4.3 \\
\hline
\end{tabular}

\begin{tabular}{|l|l|l|l|l|l|l|l|l|}
\hline 18 & 43 & 10 & 1200 & 60 & 9 & 60 & 317 & 2.6 \\
\hline
\end{tabular}

\begin{tabular}{|l|l|l|l|l|l|l|l|l|}
\hline 19 & 68 & 10 & 1200 & 60 & 4 & 60 & 406 & 2.8 \\
\hline
\end{tabular}

\begin{tabular}{|l|l|l|l|l|l|l|l|l|}
\hline 20 & 56 & 25 & 900 & 40 & 6.5 & 45 & 352 & 2.3 \\
\hline
\end{tabular}

\begin{tabular}{|l|l|l|l|l|l|l|l|l|}
\hline 21 & 68 & 40 & 600 & 60 & 9 & 30 & 534 & 4 \\
\hline
\end{tabular}

\begin{tabular}{|l|l|l|l|l|l|l|l|l|}
\hline 22 & 56 & 25 & 900 & 40 & 6.5 & 45 & 366 & 2.9 \\
\hline
\end{tabular}

\begin{tabular}{|c|c|c|c|c|c|c|c|c|}
\hline 23 & 68 & 40 & 1200 & 20 & 9 & 30 & 561 & 3.5 \\
\hline
\end{tabular}

\begin{tabular}{|l|l|l|l|l|l|l|l|l|}
\hline 24 & 56 & 25 & 900 & 40 & 6.5 & 45 & 386 & 2.9 \\
\hline
\end{tabular}

\begin{tabular}{|l|l|l|l|l|l|l|l|l|}
\hline 25 & 56 & 25 & 900 & 40 & 6.5 & 45 & 412 & 2.9 \\
\hline
\end{tabular}

\begin{tabular}{|l|l|l|l|l|l|l|l|l|}
\hline 26 & 43 & 10 & 600 & 20 & 9 & 60 & 411 & 2.2 \\
\hline
\end{tabular}

\begin{tabular}{|l|l|l|l|l|l|l|l|l|}
\hline 27 & 43 & 10 & 1200 & 20 & 9 & 30 & 341 & 1.6 \\
\hline
\end{tabular}

\begin{tabular}{|l|l|l|l|l|l|l|l|l|}
\hline 28 & 68 & 40 & 600 & 20 & 4 & 60 & 338 & 3.4 \\
\hline
\end{tabular}

\begin{tabular}{|l|l|l|l|l|l|l|l|l|}
\hline 29 & 68 & 40 & 600 & 20 & 9 & 30 & 430 & 2.8 \\
\hline
\end{tabular}

\begin{tabular}{|l|l|l|l|l|l|l|l|l|}
\hline 30 & 43 & 10 & 600 & 60 & 9 & 30 & 435 & 1.8 \\
\hline
\end{tabular}

\begin{tabular}{|l|l|l|l|l|l|l|l|l|}
\hline 31 & 43 & 10 & 600 & 60 & 9 & 60 & 374 & 3.4 \\
\hline 32 & 43 & 10 & 600 & 60 & 4 & 60 & 325 & 2.2 \\
\hline
\end{tabular}

\begin{tabular}{|l|l|l|l|l|l|l|l|l|}
\hline 32 & 43 & 10 & 600 & 60 & 4 & 60 & 325 & 2.2 \\
\hline 33 & 68 & 40 & 1200 & 60 & 4 & 60 & 453 & 3.1 \\
\hline
\end{tabular}

\begin{tabular}{|l|l|l|l|l|l|l|l|l|}
\hline 33 & 68 & 40 & 1200 & 60 & 4 & 60 & 453 & 3.1 \\
\hline
\end{tabular}

\begin{tabular}{|l|l|l|l|l|l|l|l|l|}
\hline 34 & 43 & 10 & 1200 & 20 & 4 & 60 & 177 & 2.5 \\
\hline 35 & 56 & 25 & 900 & 40 & 6.5 & 45 & 350 & 2.9 \\
\hline
\end{tabular}

\begin{tabular}{|l|l|l|l|l|l|l|l|l|}
\hline 35 & 56 & 25 & 900 & 40 & 6.5 & 45 & 350 & 2.9 \\
\hline
\end{tabular}

\begin{tabular}{|l|l|l|l|l|l|l|l|l|}
\hline 36 & 68 & 40 & 600 & 20 & 9 & 60 & 362 & 3.4 \\
\hline
\end{tabular}

\begin{tabular}{|l|l|l|l|l|l|l|l|l|}
\hline 37 & 68 & 40 & 1200 & 60 & 9 & 30 & 488 & 2.5 \\
\hline
\end{tabular}

\begin{tabular}{|l|l|l|l|l|l|l|l|l|}
\hline 38 & 68 & 40 & 600 & 60 & 4 & 30 & 340 & 2.5 \\
\hline
\end{tabular}

\begin{tabular}{|l|l|l|l|l|l|l|l|l|}
\hline 39 & 68 & 40 & 1200 & 20 & 4 & 60 & 471 & 2.7 \\
\hline
\end{tabular}

\begin{tabular}{|l|l|l|l|l|l|l|l|l|}
\hline 40 & 68 & 40 & 1200 & 60 & 4 & 30 & 452 & 2.4 \\
\hline
\end{tabular}

\begin{tabular}{|l|l|l|l|l|l|l|l|l|}
\hline 41 & 56 & 25 & 900 & 40 & 6.5 & 15 & 574 & 0.6 \\
\hline 42 & 56 & 25 & 900 & 0 & 6.5 & 45 & 653 & 2 \\
\hline
\end{tabular}

\begin{tabular}{|c|c|c|c|c|c|c|c|c|}
\hline 42 & 56 & 25 & 900 & 0 & 6.5 & 45 & 653 & 2 \\
\hline
\end{tabular}

\begin{tabular}{|l|l|l|l|l|l|l|l|l|}
\hline 43 & 56 & 25 & 1500 & 40 & 6.5 & 45 & 271 & 2.2 \\
\hline
\end{tabular}

\begin{tabular}{|c|c|c|c|c|c|c|c|c|}
\hline 44 & 56 & 55 & 900 & 40 & 6.5 & 45 & 347 & 2.1 \\
\hline
\end{tabular}

\begin{tabular}{|c|c|c|c|c|c|c|c|c|}
\hline 45 & 56 & 25 & 900 & 40 & 1.5 & 45 & 232 & 2 \\
\hline
\end{tabular}

\begin{tabular}{|l|l|l|l|l|l|l|l|l|}
\hline 46 & 56 & 25 & 900 & 40 & 6.5 & 45 & 356 & 2.1 \\
\hline
\end{tabular}

\begin{tabular}{|l|l|l|l|l|l|l|l|l|}
\hline 47 & 31 & 25 & 900 & 40 & 6.5 & 45 & 138 & 1.7 \\
\hline
\end{tabular}

\begin{tabular}{|l|l|l|l|l|l|l|l|l|}
\hline 48 & 81 & 25 & 900 & 40 & 6.5 & 45 & 721 & 4.9 \\
\hline
\end{tabular}

\begin{tabular}{|l|l|l|l|l|l|l|l|l|}
\hline 49 & 56 & 25 & 900 & 40 & 6.5 & 45 & 380 & 2 \\
\hline
\end{tabular}

\begin{tabular}{|l|l|l|l|l|l|l|l|l|}
\hline 50 & 56 & 25 & 900 & 80 & 6.5 & 45 & 335 & 2.1 \\
\hline
\end{tabular}

\begin{tabular}{|l|l|l|l|l|l|l|l|l|}
\hline 51 & 56 & 25 & 900 & 40 & 6.5 & 75 & 295 & 3.2 \\
\hline
\end{tabular}

\begin{tabular}{|l|l|l|l|l|l|l|l|l|}
\hline 52 & 56 & 25 & 300 & 40 & 6.5 & 45 & 561 & 1.9 \\
\hline
\end{tabular}

\begin{tabular}{|l|l|l|l|l|l|l|l|l|}
\hline 53 & 56 & 25 & 900 & 40 & 11.5 & 45 & 488 & 1.8 \\
\hline
\end{tabular}

\begin{tabular}{|l|l|l|l|l|l|l|l|l|}
\hline 54 & 56 & -5 & 900 & 40 & 6.5 & 45 & 288 & 1.6 \\
\hline
\end{tabular}


International Journal of Applied Engineering Research ISSN 0973-4562 Volume 10, Number 18 (2015) pp 39239-39246

(C) Research India Publications. https://dx.doi.org/10.37622/IJAER/10.18.2015.39239-39246

\section{R.S.M. Model Construction}

TABLE 5: Prediction spreadsheet with corresponding power consumptions in HT 100

\begin{tabular}{|c|c|c|c|c|c|c|c|c|c|}
\hline $\mathrm{SL}$ & & Model 1 & & & Model 2 & & & Model 3 & \\
\hline & $\mathrm{R}_{\mathrm{a}}$ (Obs.) & $\mathrm{R}_{\mathrm{a}}$ (Pred.) & (Watt) & $\mathrm{R}_{\mathrm{a}}$ (Obs.) & $\mathrm{R}_{\mathrm{a}}$ (Pred.) & (Watt) & $\mathrm{R}_{\mathrm{a}}$ (Obs.) & $R_{a}$ (Pred.) & (Watt) \\
\hline 1 & 325 & 323.237513 & \begin{tabular}{|l|l} 
& 1.8 \\
\end{tabular} & 340 & 332.93884 & 1.8 & 334 & 323.082459 & 1.7 \\
\hline 2 & 456 & 464.605161 & 3.6 & 465 & 468.447968 & 3.6 & 469 & 470.364828 & 3.6 \\
\hline 3 & 529 & 539.355161 & 3.7 & 24 & 533.947968 & 3.7 & 522 & 530.1 & 3.7 \\
\hline 4 & 276 & 174.335751 & 1.5 & 290 & 277.554547 & 1.5 & 295 & 262.40645 & 1.5 \\
\hline 5 & 433 & 466.029566 & \begin{tabular}{|l|l|}
5.9 \\
\end{tabular} & 421 & 456.680715 & 2.9 & 422 & 453.117676 & 2.7 \\
\hline 6 & 446 & 450.017569 & 1.7 & 458 & 460.986366 & 1.7 & 458 & 460.6 & 1.7 \\
\hline 7 & 303 & 323.881757 & \begin{tabular}{l|l}
7.2 \\
\end{tabular} & 308 & 324.812921 & 2.2 & 300 & 317.67982 & 2.2 \\
\hline 8 & 388 & 388.651493 & \begin{tabular}{|l|l}
3 & 3.1 \\
\end{tabular} & 383 & 390.080148 & 3.1 & 384 & 388.805298 & 3.1 \\
\hline 9 & 370 & 388.651493 & \begin{tabular}{|l|}
3.1 \\
\end{tabular} & 373 & 390.080148 & 3.1 & 382 & 388. & 3.1 \\
\hline 10 & 381 & 388.651493 & 3 & 35 & 390.0 & 3 & 384 & 388 & 3.1 \\
\hline 11 & 519 & 439.281471 & 3.9 & 517 & 472.074298 & 3.9 & 519 & 485.581661 & 3.9 \\
\hline 12 & 452 & 474.644243 & 3 & 458 & 481.874081 & 3.2 & 454 & 482.59736 & 3.0 \\
\hline 13 & 422 & 430.605161 & 3.3 & 20 & 423. & 3.3 & 429 & 28 & 3.3 \\
\hline 14 & 502 & 74709 & 3.8 & 07 & 3331 & 3.5 & 503 & 387 & 3.8 \\
\hline 15 & 296 & 264.545143 & \begin{tabular}{l|l}
3 & 2.2 \\
\end{tabular} & 294 & 258.669616 & 2.2 & 285 & 252.043711 & 2.2 \\
\hline 16 & 363 & 415 & $\begin{array}{l}2.3 \\
\end{array}$ & 370 & 994 & 3.3 & 377 & 65 & 3.3 \\
\hline 17 & 526 & 548 & \begin{tabular}{l|l}
7 & 4.3 \\
\end{tabular} & 535 & 7057 & 4.3 & 534 & 833 & 4.3 \\
\hline 18 & 310 & 275.351376 & 2.6 & 313 & 257.228611 & 2.6 & 317 & 300.695905 & 2.6 \\
\hline 19 & 395 & 405.355161 & 2.8 & 398 & 407.9 & 2.8 & 406 & 828 & 2.8 \\
\hline 20 & 357 & 388.6 & \begin{tabular}{|l|l} 
& 2.3 \\
\end{tabular} & 58 & 148 & 2.3 & 2 & 98 & 2.3 \\
\hline 21 & 534 & 500.12238 & 4 & 539 & 3388 & 4.1 & 534 & 0752 & 4 \\
\hline 22 & 368 & 388.651493 & 2.9 & 367 & 390.080148 & 2.9 & 366 & 388.805298 & 2.9 \\
\hline 23 & 553 & 571.2 & 3 & 5 & 754 & 3.5 & 51 & 37 & 3.5 \\
\hline 24 & 377 & 388.651493 & \begin{tabular}{|l|} 
\\
\end{tabular} & 378 & 148 & 2.9 & 386 & 388 & 2.9 \\
\hline 25 & 395 & 388.651493 & \begin{tabular}{|l|}
3.9 \\
\end{tabular} & 390 & 390.0 & 2.9 & 412 & 388 & 2.9 \\
\hline 26 & 402 & 396 & 2 & 405 & 429 & 2.2 & 411 & 32 & 2.2 \\
\hline 27 & 340 & 405.054197 & 1.6 & 342 & 406.1 & 1.6 & 341 & 353.7 & 1.6 \\
\hline 28 & 335 & 368.659496 & 3.4 & 337 & 521 & 3.4 & 338 & 37 & 3.4 \\
\hline 29 & 430 & 483.5 & \begin{tabular}{|l|l|}
5.9 \\
\end{tabular} & 434 & 486. & 2.9 & 430 & 415. & 2.8 \\
\hline 30 & 449 & 467.746567 & \begin{tabular}{l|l}
7.8 \\
\end{tabular} & 43 & 1191 & 1.8 & 435 & 006 & 1.8 \\
\hline 31 & 377 & 408.2658 & 3.4 & 370 & 403. & 3.4 & 374 & 345 & 3.4 \\
\hline 32 & 328 & 292.814748 & \begin{tabular}{|l|l} 
& 2.2 \\
\end{tabular} & 327 & 290. & 2.2 & 325 & 292.672824 & 2.2 \\
\hline 33 & 445 & 443.8 & 3.1 & 18 & 3612 & 3.1 & 453 & 286 & 3.1 \\
\hline 34 & 174 & 171.622378 & 2.5 & 171 & 171.813785 & 2.5 & 177 & 174.634076 & 2.5 \\
\hline 35 & 356 & 388.651493 & 2.9 & 353 & 390.080148 & 2.9 & 350 & 388.805298 & 2.9 \\
\hline 36 & 363 & 313.401044 & 3.4 & 365 & 462.847966 & 3.4 & 362 & 337.984803 & 3.4 \\
\hline 37 & 487 & 509.159496 & 2.5 & 482 & 510.007703 & 2.5 & 488 & 515.343377 & 2.5 \\
\hline 38 & 344 & 318.120104 & 2.5 & 348 & 414.892498 & 2.5 & 340 & 307.679091 & 2.5 \\
\hline 39 & 466 & 451.896149 & 2.7 & 460 & 444.767663 & 2.7 & 471 & 448.561346 & 2.7 \\
\hline 40 & 444 & 425.419573 & 2.4 & 447 & 427.403085 & 2.4 & 452 & 433.286901 & 2.4 \\
\hline 41 & 577 & 539.06865 & 0.7 & 580 & 523.067457 & 0.7 & 574 & 606.358231 & 0.6 \\
\hline 42 & 659 & 612.450252 & 2.1 & 658 & 589.379365 & 2 & 653 & 638.142804 & 2 \\
\hline 43 & 273 & 329.813888 & \begin{tabular}{|l|}
3.2 \\
\end{tabular} & 279 & 331.243001 & 2.2 & 271 & 257.311741 & 2.2 \\
\hline 44 & 355 & 361.440076 & 2.2 & 351 & 365.533072 & 2.1 & 347 & 360.544488 & 2.1 \\
\hline 45 & 236 & 297.932287 & $\begin{array}{l}7.2 \\
7\end{array}$ & 237 & 301.20382 & 2 & 232 & 258.778133 & 2 \\
\hline 46 & 369 & 388.651493 & \begin{tabular}{|l|}
3.1 \\
\end{tabular} & 363 & 390.080148 & 2.1 & 356 & 388.805298 & 2.1 \\
\hline 47 & 140 & 205.115284 & 1.7 & 144 & 210.265035 & 1.7 & 138 & 163.58098 & 1.7 \\
\hline 48 & 738 & 703.187702 & 4.9 & 732 & 664.89526 & 4.9 & 721 & 688.029615 & 4.9 \\
\hline 49 & 387 & 388.651493 & \begin{tabular}{|l|l|}
3.0 \\
\end{tabular} & 381 & 390.080148 & 2 & 380 & 388.805298 & 2 \\
\hline 50 & 343 & 354.852734 & 2.1 & 341 & 355.78093 & 2.1 & 335 & 353.467791 & 2.1 \\
\hline 51 & 302 & 332.234336 & 3.2 & 306 & 332.092838 & 3.2 & 295 & 331.968826 & 3.2 \\
\hline 52 & 561 & 511.489098 & \begin{tabular}{|l|l|}
3 & 1.9 \\
\end{tabular} & 569 & 448.917294 & 1.9 & 561 & 542.922336 & 1.9 \\
\hline 53 & 498 & 479.370699 & $\begin{array}{l}3.8 \\
\end{array}$ & 492 & 478.956475 & 1.8 & 488 & 475.832463 & 1.8 \\
\hline 54 & 286 & 305.86291 & 1.6 & 284 & 414.627223 & 1.4 & 288 & 264.933893 & 1.6 \\
\hline
\end{tabular}

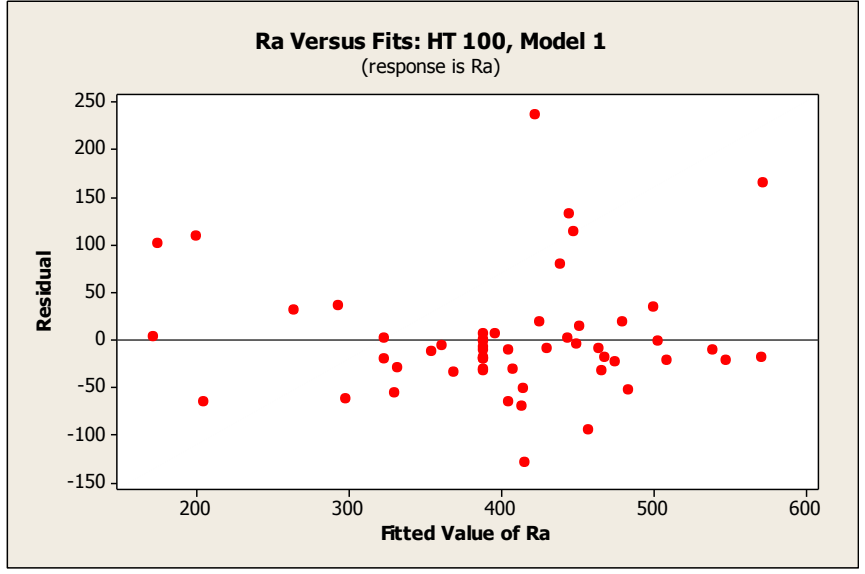

Fig. 2: Ra versus Fits plot: HT 100- Model 1

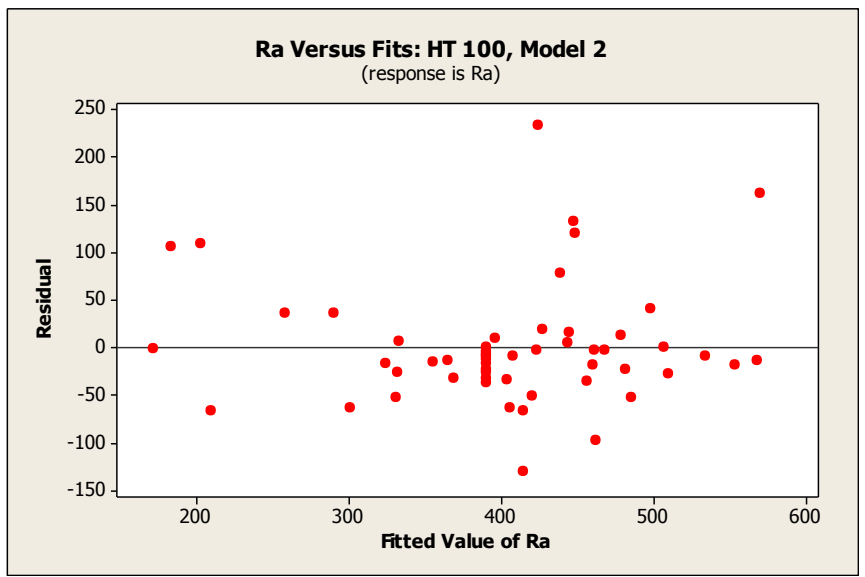

Fig. 3: $R_{\mathbf{a}}$ versus Fits plot: HT 100- Model 2

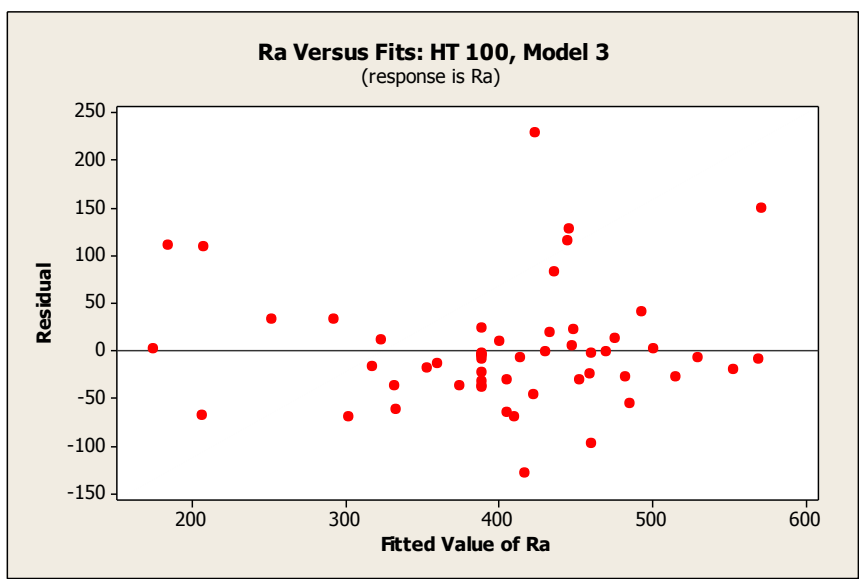

Fig. 4: $\mathbf{R}_{\mathrm{a}}$ versus Fits plot: HT 100- Model 3 


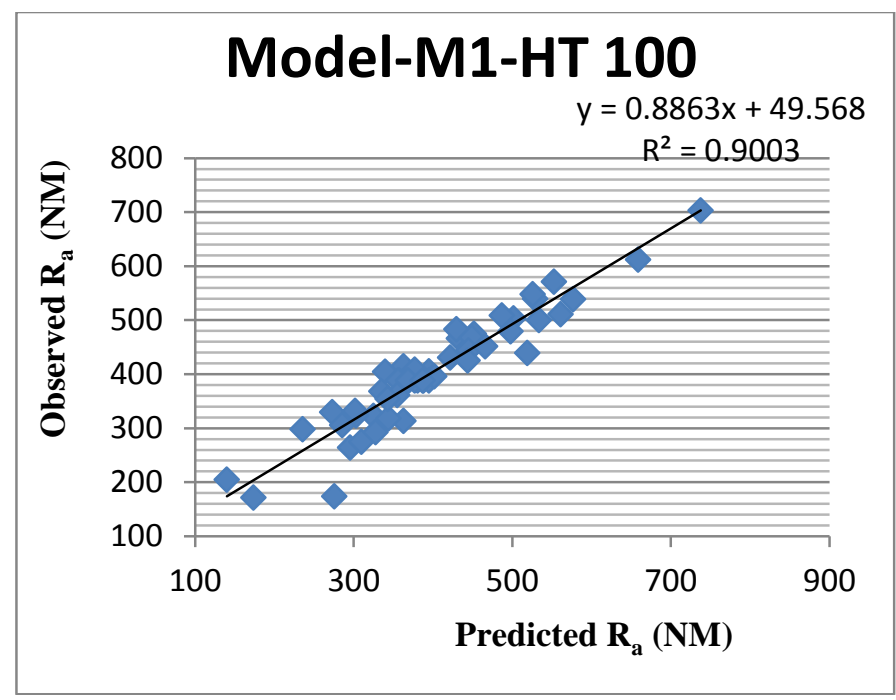

Fig. 5: Predictions against Observations of $R_{a}$ for ModelM1-HT 100

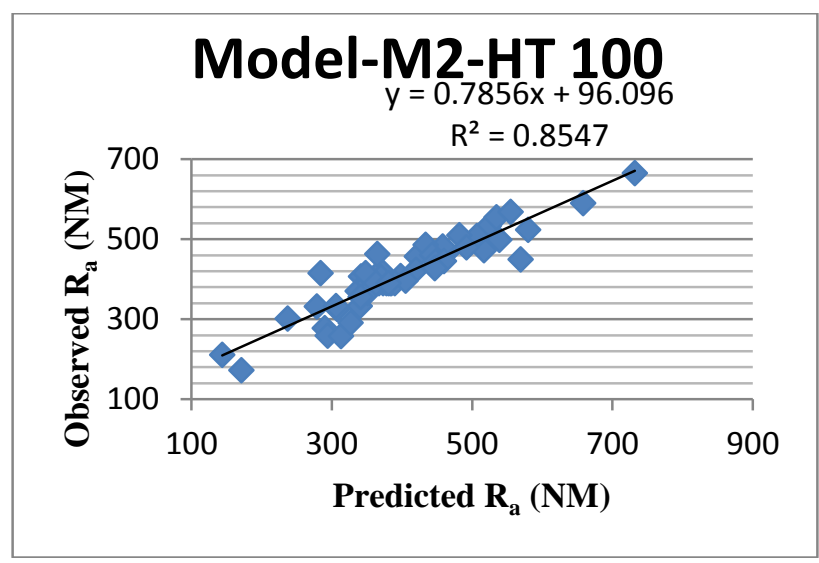

Fig. 6: Predictions against Observations of $R_{a}$ for ModelM2-HT 100

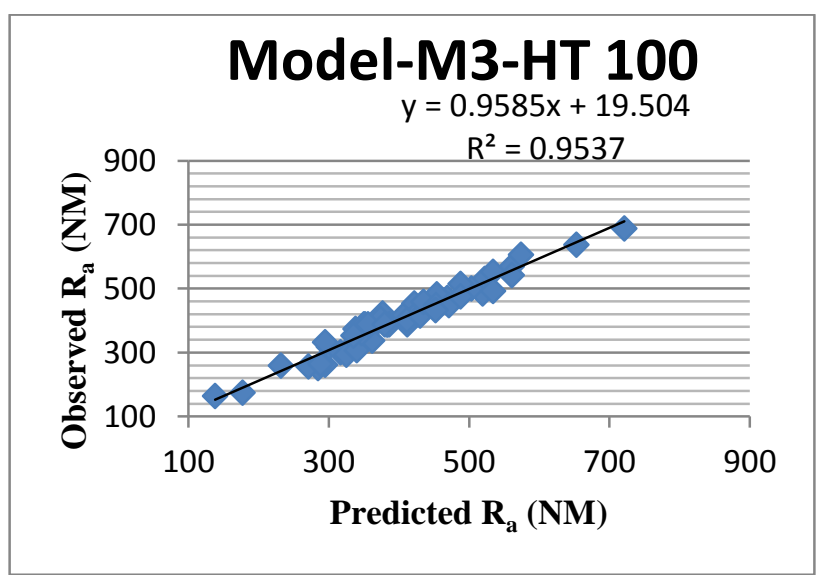

Fig. 7: Predictions against Observations of $\boldsymbol{R}_{a}$ for ModelM3-HT 100

Fig. 2 to 4 shows the graphical representation of $R_{a}$ versus fits which implicates the goodness between observed and predicted response. The $R^{2}$ values and the slope of predictions $\mathrm{R}_{\mathrm{a}}$ (component of surface roughness) has been represented by Fig.5 to Fig.7 The correlation coefficients of the model 1, model 2 \& model 3are 0.9003, 0.8547 and 0.9537 respectively. It shows a good relationship between the two values. Its gradients are also $0.8863,0.7856$ and 0.9585 which are close to unity.

\section{Modeling Result}

The following table referred to correlation coefficient between the observed and predicted values of surface roughness and root mean square error. It is very clear that higher the correlation coefficient and lower the root mean square error leads to best models. The third models of HT 100 have been selected.

Table 6: Summary of $\boldsymbol{R}^{2}$ values of RSM modeled data

\begin{tabular}{|c|c|c|c|c|c|c|c|}
\hline Material & Model & \begin{tabular}{|c|}
$R^{2}$ \\
Value
\end{tabular} & Equation & \begin{tabular}{|c|} 
Average \\
Prediction \\
$\mathbf{R}_{\mathrm{a}}$ \\
(NM)
\end{tabular} & \begin{tabular}{|c} 
Root \\
Mean \\
Square \\
Error \\
(Mg/Min)
\end{tabular} & \begin{tabular}{|c|} 
Percentage \\
RMSE \\
$(\%)$
\end{tabular} & \begin{tabular}{|c|} 
Average \\
$\%$ \\
RMSE
\end{tabular} \\
\hline \multirow[t]{3}{*}{ HT 100} & M1 & 0.9003 & $\begin{array}{c}y=0.8863 x+ \\
49.568\end{array}$ & 406.37 & 34.65 & 8.52 & \multirow[t]{3}{*}{8.246} \\
\hline & $\mathrm{M} 2$ & 0.8547 & $y=0.7856 x+$ & 413.16 & 43.17 & 10.44 & \\
\hline & M3 & 0.9537 & $y=0.9585 x+$ & 405.94 & 23.47 & 5.78 & \\
\hline
\end{tabular}

\section{Conclusion for Modelling:}

The foregoing study shows that it is possible to construct reliable RSM models for surface roughness parameter of the honing process applied to the cylinder liner of a motorbike. The chief features of the model are as follows:

(i) The central composite design of experiment is more robust than other existing modeling techniques used in honing which has already been discussed in literature review.

(ii) It is the most compatible approach for the modeling of honing operation using very small experimental effort.

(iii) It is the most compatible approach for the modeling of honing operation using very small experimental effort.

(iv) It is the most compatible approach for the modeling of honing operation using very small experimental effort.

(v) MINITAB 17 has been used for the prediction of surface roughness of the cylinder liner by incorporating the all process parameters in to it.

Based on the correlation coefficient and root mean square error approach, the best models were selected as third models of HT 100.

\section{References:}

[1] Abouelatta, O.B. and Mald, J. (2001), "Surface roughness prediction based on cutting parameters 
and tool vibrations in turning operations," Journal of Materials Processing Technology, vol.118, pp269277.

[2] Armergo, E.J.A. and Brown, R.H. (1969), The machining of metals, Prentice-Hall Inc., Englewood Cliffs, New Jersey, pp370.

[3] Arora, P.K. (2008), "Statistical modelling of surface roughness in turning process," M.Tech. Dissertation, Department of Mechanical Engineering, CITM, MD University, Rohtak, Haryana, India.

[4] ASME, (1996), "Surface Texture (Surface roughness, Waviness, and Lay): An American Standard," ASME B46.1-1995 (Revision of ANSI/ASME B46.1-1985), and ASME Press, New York.

[5] Baek, D.K, Ko, T.J., and Kim, H.S. (2001), "Optimization of feed rate in a face milling operation using a surface roughness model," International Journal of Machine Tools and Manufacture, vol.41, pp451-462.

[6] Bernados, P.G. and Vosniako, G.C. (2002), "Predicting surface roughness in $\mathrm{CNC}$ face milling using neural networks and Taguchi's design of experiments," Robotics and Computer Integrated Manufacturing, vol.18, pp343-354.

[7] Bhattacharya, A., Faria-Gonzalez, R. and Ham, I. (1970), "Regression analysis for predicting surface finish and its application in the determination of optimum machining conditions," ASME Journal of Engineering for Industry, vol.4, pp711-714.

[8] Boothryod, G. and Knight, W.A. (1989), Fundamentals of machining and machine tools, 2nd edition, New York: Marcel Dekker.

[9] Box, G.E.P, Hunter, W.G., and Hunter, J.S. (1978), "Statistics for experimenter: An Introduction to design, data analysis, and model building," New York, John Wiley and Sons.

[10] Chavan P.S. et al (2013), "Effect Of Honing Process Parameters On Surface Quality Of Engine Cylinder Liners" International Journal of Engineering Research \& Technology, vol 2, No 4, ISSN 22780181, pp 98-107

[11] Das, S.R et al (2014), "Surface Roughness, Machining Force and FlankWear in Turning of Hardened AISI 4340 Steel with Coated Carbide Insert: Cutting Parameters Effects" International Journal of Automotive Engineering, vol 4, No 3, pp 758-768

\section{Authors}

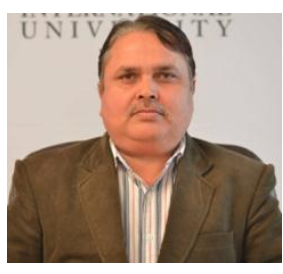

Mr. B. N. Tripathi

Research Scolar, ISM/IIT Dhanbad Teaching \& Research Experience - 13 years Research Publications - More than 05



\section{Dr. N. K. Singh}

Associate Professor, ISM/IIT Dhanbad Teaching \& Research Experience - 28 years Research Publications - More than 30. 